OPEN ACCESS

Edited by:

Daniel P. Bailey,

University of Bedfordshire,

United Kingdom

Reviewed by:

Gareth A. Wallis,

University of Birmingham,

United Kingdom

Paolo Capodaglio,

Istituto Auxologico Italiano (IRCCS),

Italy

*Correspondence:

Jennifer L. Miles-Chan

jenniferlynn.miles@unifr.ch

Specialty section:

This article was submitted to

Exercise Physiology,

a section of the journal

Frontiers in Physiology

Received: 25 April 2017

Accepted: 31 May 2017

Published: 22 June 2017

Citation:

Miles-Chan JL and Dulloo AG (2017)

Posture Allocation Revisited: Breaking

the Sedentary Threshold of Energy

Expenditure for Obesity Management.

Front. Physiol. 8:420

doi: 10.3389/fphys.2017.00420

\section{Posture Allocation Revisited: Breaking the Sedentary Threshold of Energy Expenditure for Obesity Management}

\author{
Jennifer L. Miles-Chan * and Abdul G. Dulloo \\ Department of Medicine Physiology, University of Fribourg, Fribourg, Switzerland
}

There is increasing recognition that low-intensity physical activities of daily life play an important role in achieving energy balance and that their societal erosion through substitution with sedentary (mostly sitting) behaviors, whether occupational or for leisure, impact importantly on the obesity epidemic. This has generated considerable interest for better monitoring, characterizing, and promoting countermeasures to sedentariness through a plethora of low-level physical activities (e.g., active workstations, standing desks, sitting breaks), amid the contention that altering posture allocation (lying, sitting, standing) can modify energy expenditure to impact upon body weight regulation and health. In addressing this contention, this paper first revisits the past and more recent literature on postural energetics, with particular emphasis on potential determinants of the large inter-individual variability in the energy cost of standing and the impact of posture on fat oxidation. It subsequently analyses the available data pertaining to various strategies by which posture allocations, coupled with light physical activity, may increase energy expenditure beyond the sedentary threshold, and their relevance as potential targets for obesity management.

Keywords: energy expenditure, posture, obesity, spontaneous physical activity, thermogenesis

Evolutionary scientists still are not sure why our ancestors became bipedal, but along with the evolution of the major traits and behaviors that define humans (such as large brains, language, art, technology), walking upright - and the performance of a plethora of activities while maintaining standing posture-is a most fundamental human characteristic (Wayman, 2012). Yet, Modern Man (and Woman) is sedentary for much larger proportions of the day than ever before ( $\mathrm{Ng}$ and Popkin, 2012). Indeed, a modern lifestyle involves a large variety of seated activities, whether they be occupational or for leisure. The rise in the prevalence of such activities has led to the notion of a major shift in posture allocation from standing in favor of sitting on a population basis. With this belief has come a myriad of correlative analyses showing a positive relationship between sitting time and cardiometabolic disease risk (Henson et al., 2016; Young et al., 2016; Tigbe et al., 2017). In addition, studies have now shown that obese individuals spend significantly more time sitting and less time standing than their lean counterparts (Levine et al., 2005; Johannsen et al., 2008). This therefore begs the question as to whether or not modifying posture allocation could sufficiently alter energy expenditure (EE) in order to impact body weight regulation over time; an idea that requires us to revisit the literature concerning postural energetics. 


\section{HISTORICAL INTEREST IN POSTURE ALLOCATION}

Whilst, the interest in posture allocation as a potential target in obesity prevention has increased over recent years, interest in quantifying its energetic cost originated in an entirely different scientific and social context.

During the first half of the twentieth century there was considerable attention on improving guidelines of energy requirements at the individual and population level; with such information required to provide aid and assistance to developing and war-torn countries as well as to optimize military performance. A major hurdle in estimating energy requirements was the need to establish a database of the energy cost of common, standardized physical activities. The breakthrough came in the 1940s with the development of the KofranyiMichaelis or Max Planck respirometer (Passmore and Durnin, 1955). Despite being comparatively heavy compared to modern devices, this respirometer allowed researchers for the first time to measure EE by indirect calorimetry during a host of dailylife activities, in the field, and in very diverse populations (for example: Passmore et al., 1952; Passmore and Durnin, 1955).

It is noticeable from these early studies that considerable emphasis was put on variability in the energy cost of standardized low-level physical activities both between and within individuals - an important aspect of human energetics which has been largely overlooked in more recent studies. For example, the classic studies of Passmore et al. (1952) and Edholm et al. (1955) both reported large inter-individual variability in the energy cost for performing the same activity, with EE during standing compared to sitting increasing by anything from $\sim 0 \%$ to $>30 \%$ in individuals from relatively homogenous study groups. In addition to this inter-individual variability, Miller (1982) reported intra-individual variability in the energy cost of sitting and standing in six individuals to range from 5 to $13 \%$ and 4 to $7 \%$, respectively.

It was not until the demonstration by Zurlo et al. (1992) of an inverse correlation between spontaneous physical activity (SPA) and body weight gain in Pima Indians that research interest in low-level physical activities and sedentary behaviors in the context of obesity development really began; SPA being a term that encapsulates posture maintenance, fidgeting and other essentially subconscious low-level movement (Dulloo et al., 2012). However, the watershed moment occurred at the turn of this century, with the observation by Levine et al. (1999) of an increase in non-exercise activity thermogenesis (NEAT) in individuals showing a relative resistance to fat gain during overfeeding; NEAT being estimated by subtraction of basal and postprandial EE from total daily EE. Whilst posture allocation is just one component of SPA and NEAT (Figure 1), two subsequent studies (Levine et al., 2005; Johannsen et al., 2008), each involving 10 lean and 10 obese individuals, have provided evidence of a difference in posture allocation between these two population groups-therefore highlighting a new potential target for obesity treatment and prevention.

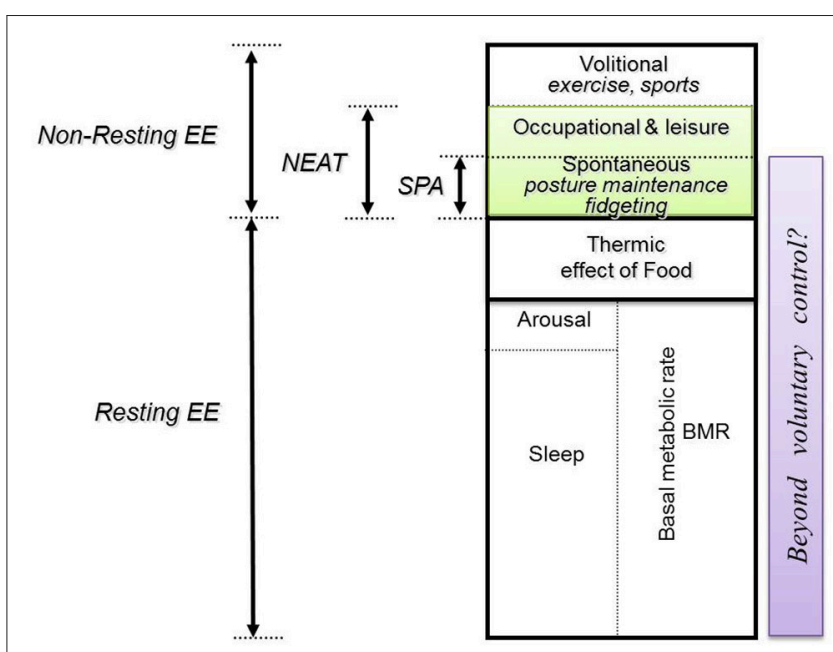

FIGURE 1 | Compartments of daily energy expenditure. Daily energy expenditure (EE) can be divided into resting and non-resting EE. Non-resting EE can further be divided into (i) volitional EE related to structured physical activities, such as sports and exercise, which are usually of

moderate-to-vigorous intensity; and (ii) non-exercise activities (NEAT). These non-exercise activities include both those under voluntary (conscious) control associated with occupation and leisure, and those that are involuntary (subconscious) in nature. This sub-compartment of spontaneous physical activity (SPA) includes low-level physical activities such as postural maintenance and fidgeting. Adapted from Dulloo et al. (2012).

\section{ENERGY COST OF POSTURE MAINTENANCE}

As a result of these two observational studies, it has been suggested that if obese individuals were to match the posture allocation of lean individuals-i.e., by re-allocating $2-2.5 \mathrm{~h}$ of sitting time to standing per day-then daily EE would be increased by $\sim 300-350 \mathrm{kcal}$ or $\sim 10-20 \%$ (Levine et al., 2005; Johannsen et al., 2008); potentially resulting in a weight loss of $\sim 15 \mathrm{~kg}$ over a year (Levine et al., 2005). These calculations are based on the following three key assumptions:

1. That standing is not a sedentary behavior, and as such its energetic cost is more than 1.5 times the energy cost of sitting at rest (i.e., > $1.5 \mathrm{METs}$ );

2. That the energy cost of standing is constant across the entire standing period regardless of duration; and,

3. That the energy cost of standing is the same or similar between individuals.

However, our analysis of the available literature reveals a number of challenges to these assumptions; these are elaborated below.

\section{Energy Cost of Steady-State Standing Posture Maintenance}

Since 1952, there have been just over 30 studies presenting measurements of both the energetic cost of standing and sitting, comprising of $>60$ experimental groups (Table 1; Passmore et al., 1952; Donald and Davidson, 1954; Edholm et al., 1955; Garry et al., 1955; Durnin and Passmore, 1967; Banerjee et al., 


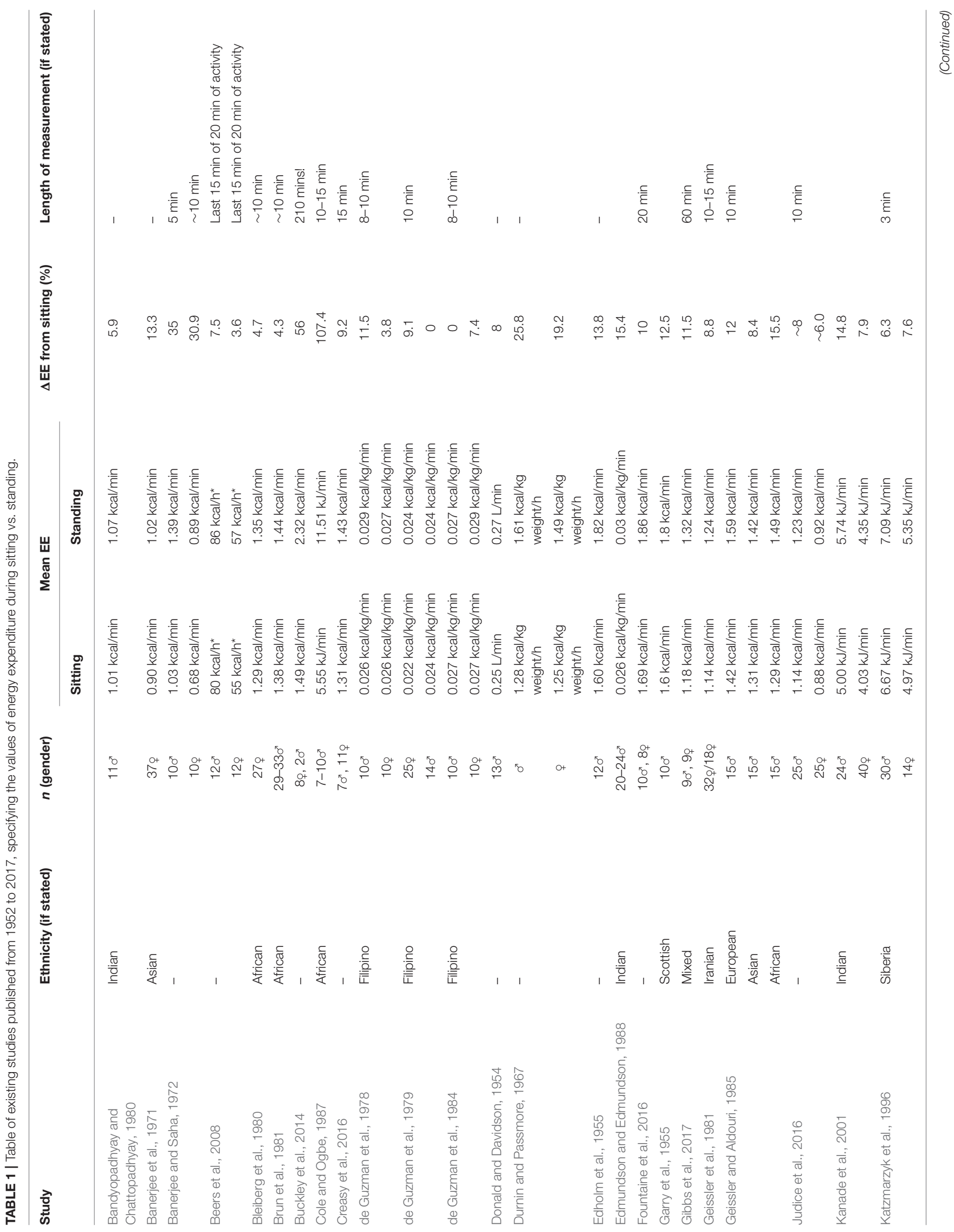




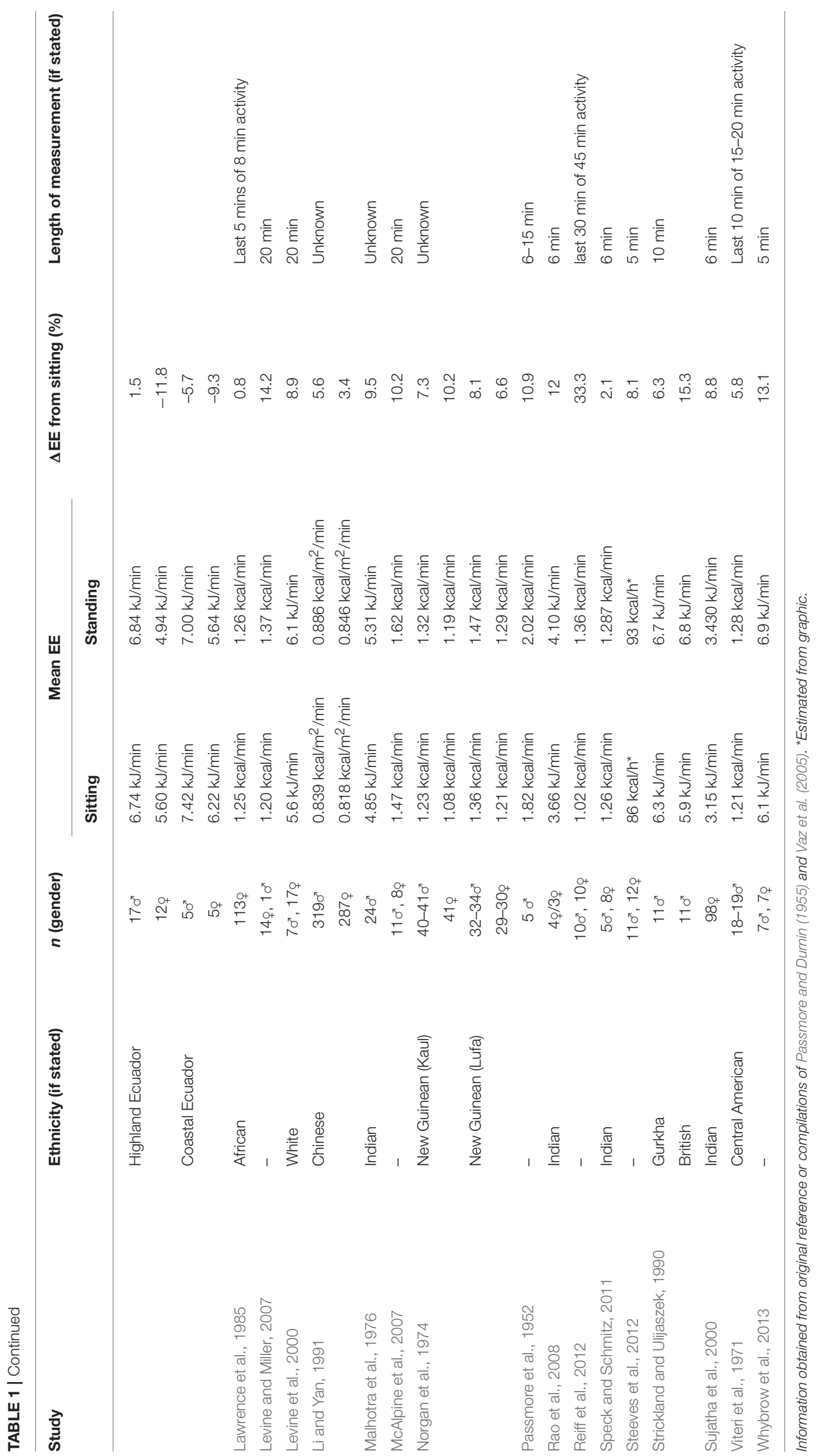


1971; Viteri et al., 1971; Banerjee and Saha, 1972; Norgan et al., 1974; Malhotra et al., 1976; de Guzman et al., 1978, 1979, 1984; Bandyopadhyay and Chattopadhyay, 1980; Bleiberg et al., 1980; Brun et al., 1981; Geissler et al., 1981; Geissler and Aldouri, 1985; Lawrence et al., 1985; Cole and Ogbe, 1987; Edmundson and Edmundson, 1988; Strickland and Ulijaszek, 1990; Li and Yan, 1991; Katzmarzyk et al., 1996; Levine et al., 2000; Sujatha et al., 2000; Kanade et al., 2001; Levine and Miller, 2007; McAlpine et al., 2007; Beers et al., 2008; Rao et al., 2008; Speck and Schmitz, 2011; Reiff et al., 2012; Steeves et al., 2012; Whybrow et al., 2013; Buckley et al., 2014; Creasy et al., 2016; Fountaine et al., 2016; Judice et al., 2016; Gibbs et al., 2017).

By comparing these values of standing relative to sitting (Figure 2), we can observe considerable variability amongst these studies, with the energy cost of standing ranging from a $10 \%$ decrease in EE during standing relative to sitting (measured in females of two subsistence-level populations in Ecuador; Katzmarzyk et al., 1996) to increases in EE of $>30 \%$ above sitting values (with one study observing a mean increase of $>100 \%$; Cole and Ogbe, 1987); with an overall mean increase in EE during standing posture maintenance of $11.6 \%$, and a median increase of $8.6 \%$, above sitting EE. It is important to note that these studies differed considerably in terms of methodology, their level of standardization, presentation of results (i.e., integrated mean over entire standing period vs. average of last $5 \mathrm{~min}$ ) and their definition of standing itself (i.e., with or without fidgeting, length of standing period), thus making direct comparison between these studies difficult. However, regardless of these inconsistencies, it appears that the true energy cost of steady-state standing posture maintenance is considerably lower than the commonly described sedentary threshold of 1.5 METs (Sedentary Behaviour Research Network, 2012).

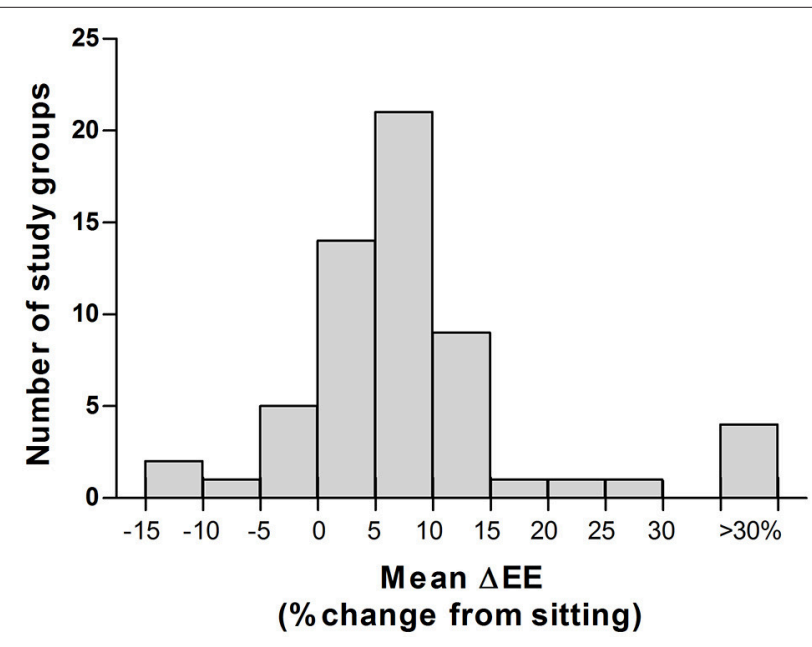

FIGURE 2 | Inter-study variability in the energy cost of standing vs. sitting. Histogram of all energy cost of standing vs sitting reported by all studies published 1952-2017 ( $n=32$ studies, 59 study groups). Mean \pm SEM: 11.6 $\pm 2.1 \%$; Median: $8.4 \%$; Range $-11.8 \%$ to $+107.4 \%$. Please refer to Table 1 for further details of individual studies.

\section{Time-Course of Energy Cost of Standing Posture Maintenance}

Investigations of the energy cost of standing posture maintenance almost exclusively present the EE during standing (and therefore the calculation of its energy cost) as an integrated mean across the entire standing period, regardless of its duration. However, there seems to be little evidence to support the notion that EE is indeed constant during standing. In fact studies conducted in our laboratory using minute-by-minute EE monitoring have shown that the majority of individuals demonstrate an initial increase in EE (most likely due to the postural transition) and then rather quickly (within $5 \mathrm{~min}$ ) decrease their EE back to sitting values (Miles-Chan et al., 2013, 2017; Monnard and Miles-Chan, 2017; Figure 3). The rise in EE during postural transitioning is expected given the large amount of muscular contraction required to move the body weight from, for example, a sitting to standing position; but it is perhaps inclusion of this transitional period of EE, rather than consideration of only the steady-state period of posture maintenance, that has led to some of the large discrepancies in calculated energy costs.

The exact mechanisms by which the majority of individuals are able to maintain a standing posture at the same energetic cost as sitting remain to be elucidated, although it appears somewhat analogous to the adaptation in energy cost observed during other physical activities. For example, a large volume of research now supports the notion that locomotion is quickly and precisely optimized in order to minimize its energetic cost. Such optimization may occur in response factors like pregnancy (Poppitt et al., 1993), load-carrying (Maloiy et al., 1986; Jones et al., 1987; Lloyd et al., 2010), or exogenous gait disturbance (Koller et al., 2015; Selinger et al., 2015), and is not unique to humans-with locomotive optimization demonstrated across a large number of species (Tucker, 1970; Alexander, 1989). Also, importantly when considering time-course of relatively short physical activities such as standing maintenance, recent studies involving the perturbation of human gait have shown that adaptations that minimize energetic cost of locomotion occur within minutes (Selinger et al., 2015); i.e., within the timescale over which standing is usually performed.

\section{Variability in Energy Cost of Standing Posture Maintenance}

As discussed earlier, there is considerable variability in the energy cost of posture maintenance in healthy individuals. Whilst a certain amount of variability may be accounted for by differences in standardization and methodology, large levels of withinstudy variability (i.e., amongst individuals measured under identical experimental conditions) strongly suggests a large degree of true biological variability. Indeed the inter-individual variability shown in the early studies of Edholm et al. (1955) and Passmore et al. (1952), is almost identical to that which we have recently observed in our laboratory using contemporary equipment (Miles-Chan et al., 2013, 2017; Monnard and MilesChan, 2017)-i.e., ranging from individuals who showed no increase in EE during steady-state standing relative to sitting ("energy savers") to those who showed sustained increases in EE 


\section{Canopy}

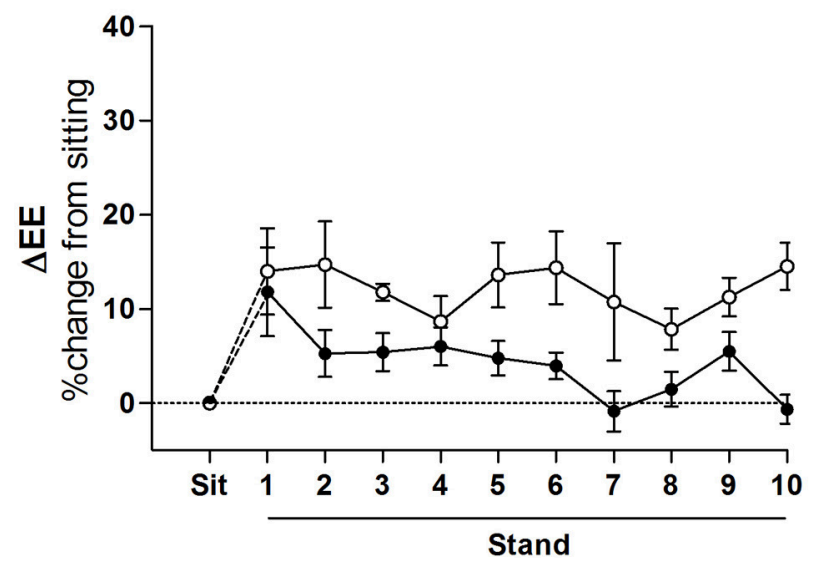

Facemask

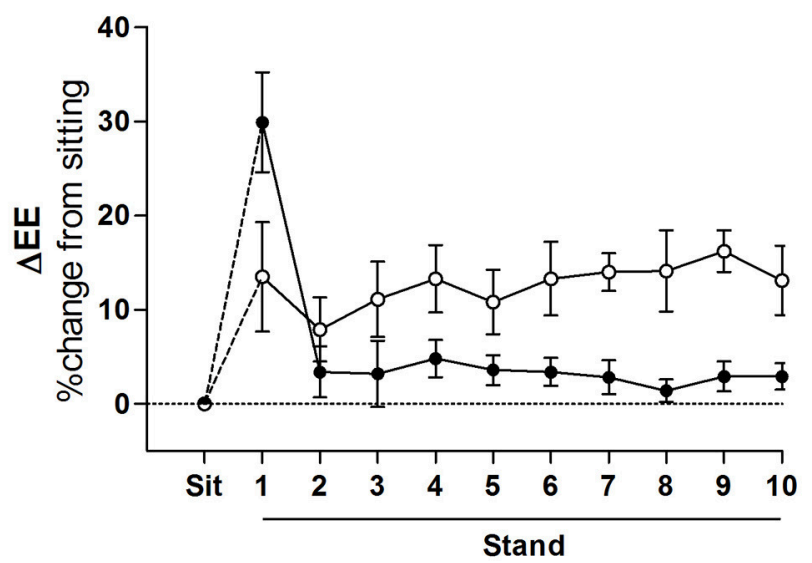

FIGURE 3 | Time course of energy cost of standing posture maintenance. Change in energy expenditure (EE) measured during 10 min of steady-state standing (i.e., after postural transition) as a percentage of resting, sitting EE. Mean \pm SEM. Left panel: measurements obtained using posture-adapted ventilated canopy indirect calorimetry (Deltatrac II, Datex-Ohmeda, Instrumentarium Corp, Helsinki, Finland) (Miles-Chan et al., 2013); Right panel: measurements obtained using facemask indirect calorimetry (Cosmed Quark, Cosmed srl, Rome, Italy) (Miles-Chan et al., 2017); Closed circles: represent "Energy-savers," i.e., those who showed little or no change in $\mathrm{EE}$ (a rise in $\mathrm{EE}$ of $<5 \%$ ) during 10 min standing period relative to sitting, and also those who increased $\mathrm{EE}$ (a rise in $\mathrm{EE}$ of $>5 \%$ ) during first 5 min of the 10 min standing period relative to sitting but subsequently decreased $E E$ (by $>30 \%$ of the rise) during the second 5 min of this standing period; $n=18$ (left panel) and 29 (right panel); Open circles: represent "Energy-spenders," i.e., those who increased EE (a rise in EE of $>5 \%$ ) during first 5 min of the 10 min standing period relative to sitting, and maintained an elevated $E E$ throughout the entire 10 min standing period (drop in EE during second 5 min $<30 \%$ of the rise in $E E$ during first 5 of standing period); $n=4$ (left panel) and 7 (right panel).

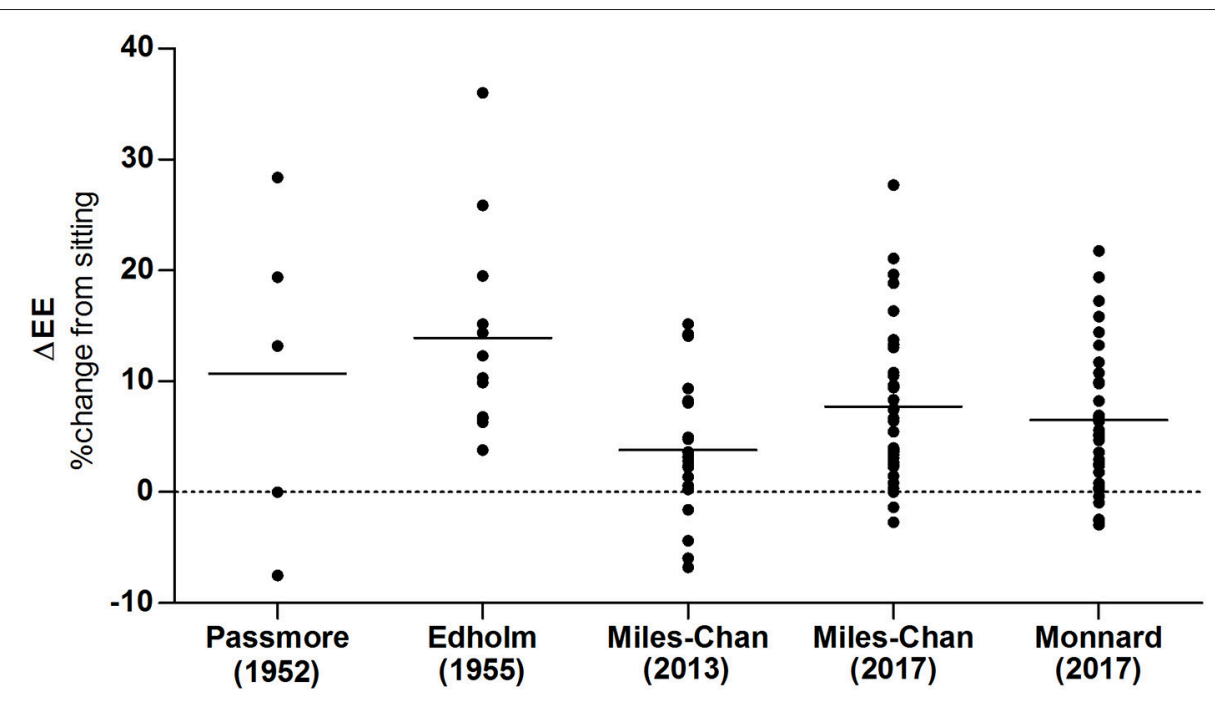

FIGURE 4 | Inter-individual (intra-study) variability in the energy cost of standing vs. sitting. Scatter plot of variability in the energy cost of standing vs. sitting between individual subjects in the studies of Edholm et al. (1955), Passmore et al. (1952), Miles-Chan et al. (2013), Miles-Chan et al. (2017), and Monnard and Miles-Chan (2017). Each point represents an individual study participant; horizontal lines indicate median and interquartile range.

of 25-35\% ("energy spenders;" Figure 4). This is in sharp contrast to a relatively low intra-individual coefficient of variation in the energy cost of standing-reported by Miller to range from 4 to $7 \%$ (Miller, 1982), and the intra-individual coefficient of variation in EE during standing within our own laboratory to range from 0 to $7 \%$ (Miles-Chan et al., 2017). Nevertheless, using standardized experimental conditions, we have yet to observe any difference in terms of sex (Miles-Chan et al., 2013, 2017) or ethnic group (Monnard and Miles-Chan, 2017) between these two EE phenotypes. Furthermore, given that during standing posture maintenance individuals appear to differ in terms of the degree and pattern of weight-shifting behavior (i.e., the redistribution of body-weight from one foot to the other), we have recently investigated if an overt difference in terms of spontaneous weight-shifting behavior could be detected between these two EE phenotypes (Miles-Chan et al., 2017). However, no 
such difference was apparent amongst the healthy young adults who participated in the study. It therefore remains unclear as to whether or not this apparent adaptive failure resides in a physiological difference between "energy spenders" and "energy savers," is related to psychological factors (for example, a strong preference for one posture over the other), or a combination of the two.

Moreover, given earlier demonstrations that the energy cost of physical activities such as walking may vary by $46 \%$ depending on energy intake (Apfelbaum et al., 1971), further investigations are warranted to assess the energy cost of standing posture maintenance in the postprandial phase, particularly given that the majority of the day is spent in the absorptive state. But perhaps most importantly, given the postulation that matching posture allocation of obese individuals to that of lean may significantly increase EE, it is of fundamental importance to comprehensively establish whether or not the energy cost of standing posture maintenance is altered in the obese state. Indeed, body geometry, and more specifically the distribution of adipose mass, has been shown to influence postural stability (Corbeil et al., 2001; Gilleard and Smith, 2007; Blaszczyk et al., 2009; Singh et al., 2009; Cruz-Gomez et al., 2011; Villarrasa-Sapina et al., 2016). With increased abdominal obesity shown to increase postural sway, and presumably increased muscle work being required to maintain balance, one might hypothesize that the energy cost of postural maintenance may be elevated in individuals with abdominal obesity or certain body morphologies, although this remains to be tested.

\section{ENERGY COST VS. CARDIOVASCULAR RESPONSE}

When considering the assessment of physical activity under free-living conditions, heart rate has traditionally been used as an objective, proxy measurement for EE. Indeed, while the recent advances in accelerometric devices are now allowing more accurate detection of body posture, commercially-available heart rate-based activity monitors are now widely used by the general public to monitor physical activity levels. However, it is important to note that although the relationship between these two variables is approximately linear during traditional, moderate-to-vigorous physical activity (Spurr et al., 1988), the same is not true of low-intensity physical activities (Ceesay et al., 1989). In order to maintain blood pressure during orthostasis, the autonomic nervous system works to increase both vasoconstriction in the extremities and heart rate. This increased heart rate persists across the standing period, and can occur in the absence of any obvious change in EE; as consistently observed in our recent studies where all individuals showed comparable increases in heart rate during steady-state standing $(\sim 15$ beats per minute), despite responses in terms of EE ranging from little or no change compared to sitting to an increase of $\sim 25 \%$ (Miles-Chan et al., 2013, 2017). Similarly, despite no detectable change in $\mathrm{EE}$, we have also shown a significant difference in heart rate during sitting compared to supine $\sim 7$ beat per minute (Miles-Chan et al., 2014). Further, dissociation between the heart rate and EE response to altered body posture can be demonstrated in our preliminary study in healthy young men, performed using a clinical tilting table. With the body weight supported entirely by the tilting table, and thereby minimizing any muscular work required for posture transition and maintenance, we were able to observe a "doseresponse" relationship between tilt angle (from supine to $60^{\circ}$ ) and heart rate, but no change in EE (Figure 5). Studies reporting values of $\mathrm{EE}$ estimated from heart rate in situations where postural allocation is not controlled (i.e., free-living conditions) should therefore be interpreted with considerable caution.

\section{BREAKING THE SEDENTARY THRESHOLD}

The energy cost of steady-state posture maintenance is relatively small ( $<35 \%$ above sitting). Bodily movements, e.g., displacement of the body (i.e., at least one step to be taken), are needed to increase EE beyond 1.5 times resting metabolic rate (Miles-Chan et al., 2017) — the level of EE commonly defined as the cut-off between sedentary and physical activities (Sedentary Behaviour Research Network, 2012). But there are two aspects of posture allocation that could potentially be exploited to increase $\mathrm{EE}$, as described below.

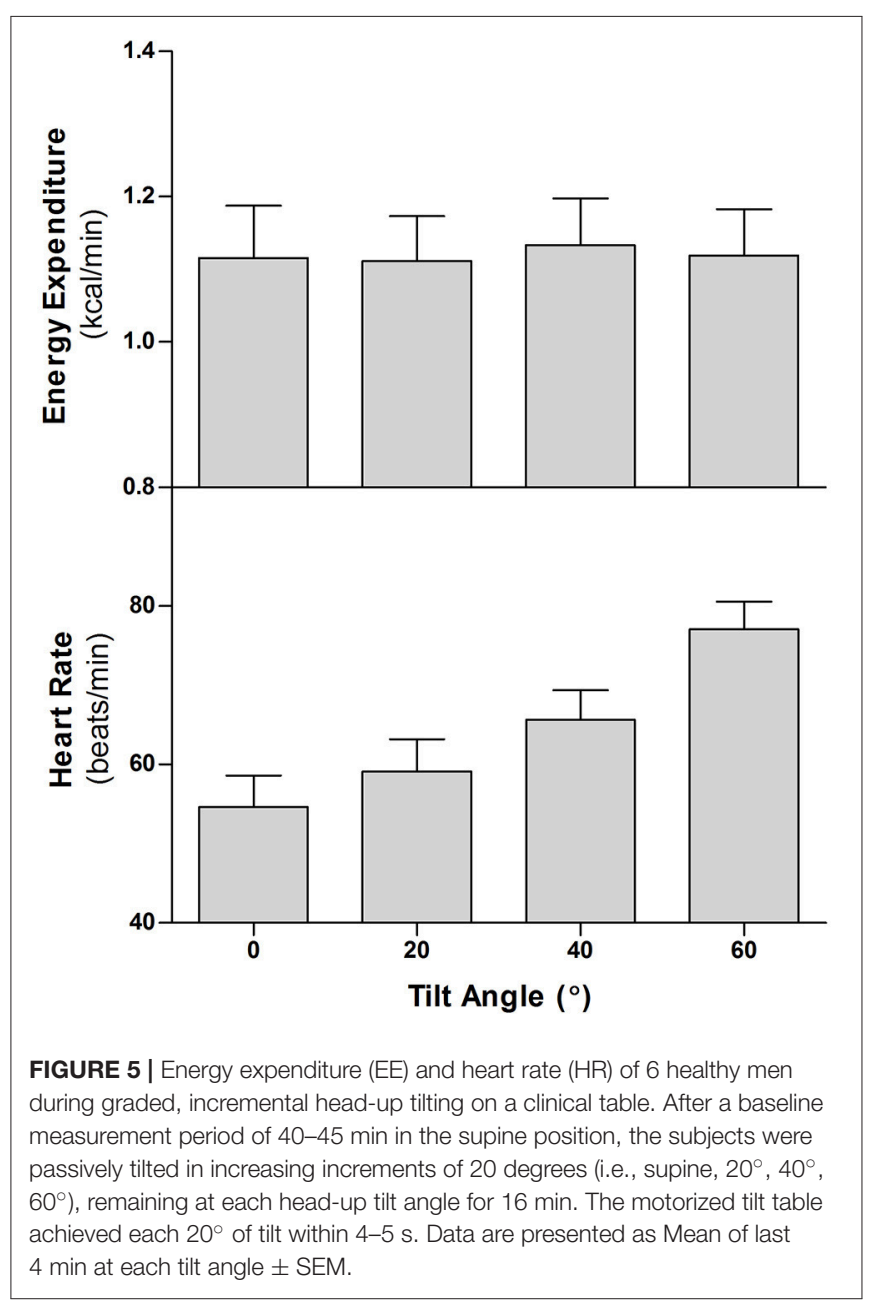




\section{Energy Cost of Muscle Activation (Isometric Contraction)}

Maintaining posture, whether upright or seated, requires a certain degree of muscle tone and isometric contraction of stabilizing muscles. As the skeletal muscles involved in this stabilization and increased tonus are comprised of predominately oxidative fibers, increasing postural muscle activation could present not only an opportunity to increase $\mathrm{EE}$, but also to increase the relative rate of fat oxidation. However, despite daily life activities consisting of a large amount of low-level isometric contraction, compared to dynamic exercise, its energy cost has been much less studied and quantified (Dulloo et al., 2017).

So how might isometric contraction be amplified in order to maximize EE during postural maintenance? Perhaps the simplest answer would be to alter posture allocation, so as to replace time spent in one posture with that of a potentially higher energetic cost (i.e., replace sitting time with standing time). However, this alone may not be sufficient to noticeably increase EE. Indeed, in addition to demonstrating that the majority of individuals $(>75 \%)$ are able to maintain a standing posture at a similar level of EE to sitting (Miles-Chan et al., 2013, 2017), we have also shown that sitting in a comfortable chair, with the body weight well-supported, does not significantly increase EE above supine levels ( $<2 \%$ difference; Miles-Chan et al., 2014). In fact, based on these findings, replacing $2.5 \mathrm{~h}$ per day of lying or sitting by standing is in itself unlikely to increase daily EE by any more than $20 \mathrm{kcal}$ (i.e., <1\%); this is considerably less than the amount postulated by others (Levine et al., 2005; Johannsen et al., 2008). Similarly, Beers et al. (2008) have calculated that even sitting on a stability (exercise) ball-where the back is not supportedwould still only result in an increase in sitting EE in the order of only around $0.07 \mathrm{kcal} / \mathrm{min}(\sim 7 \%)$. This marginal increase in EE, combined with studies showing increased levels of discomfort when sitting on such a ball compared to a traditional office chair (Gregory et al., 2006; McGill et al., 2006; Kingma and van Dieen, 2009), suggest that the use of such sitting balls does not present an effective obesity prevention/treatment strategy.

However, several other methods of enhancing muscle activation during postural maintenance have demonstrated the ability to appreciably increase EE. For example: (i) whole body vibration during standing has been shown to increase expenditure by $\sim 30 \%$ compared to standing without vibration (Fares et al., 2016); and (ii) Maffiuletti et al. (2012) have shown that standing in unstable shoes modestly increase EE (by 5\% on average) in patients with obesity as compared to conventional shoes, with increases in postural sway and electromyographic activity of the leg and foot muscle also having been demonstrated when using such shoes (Landry et al., 2010). It is perhaps worth noting that some of the large discrepancy in energetic response to these two methods of enhancing muscle activation may lie in the timescale of the muscle contraction itself-with studies in isolated muscle suggesting that a series of brief contractions may be more energetically costly than a single muscle contraction of a longer duration (Chasiotis et al., 1987; Bergstrom and Hultman, 1988; Hogan et al., 1998); the former also resulting in a larger increase in glycolysis and greater fatigue (Spriet et al., 1988; Hogan et al., 1998).

\section{Energy Cost of Postural Transitioning and Low-Level Physical Activities}

Whilst, the energy cost of maintaining posture may be marginal, the energy cost of transitioning between postures (in particular, from sitting to standing) is receiving much attention as a potential interventional target. The reasoning for this interest is two-fold: Firstly, breaking sitting time has been shown to decrease metabolic risk independently of moderate-to-vigorous physical activity (Honda et al., 2016), with length of sitting bouts positively correlated with waist circumference and obesity prevalence (Healy et al., 2008; Gupta et al., 2016), and frequent interruptions to sitting time improving postprandial glucose metabolism (Bergouignan et al., 2016), triglyceride levels, waist circumference and BMI (Hamilton et al., 2008; Healy et al., 2008). Secondly, the energy cost of postural transitioning is much higher than that of postural maintenance-with a sit-to-stand transition increasing $\mathrm{EE} \sim 35 \%$ above sitting metabolic rate (Judice et al., 2016), and showing a positive linear relationship with transition frequency (Hatamoto et al., 2016). Furthermore, the latter study (Hatamoto et al., 2016) demonstrated a four-fold increase in metabolic rate above resting during the performance of sit-tostand transitions at a rate of 15 per minute, with the exercise still perceived as "light" by the participants. Importantly, while considerable inter-individual variability can be observed in the slope of this transition frequency vs. energy cost relationship, the cost is strongly correlated with body weight, thereby indicating that increasing postural transitioning may be of particular benefit to individuals who are overweight or obese (Hatamoto et al., 2016).

As mentioned earlier, in order to consistently increase EE beyond the sedentary threshold of 1.5 times resting metabolic rate (i.e., 1.5 METs), bodily movement is required. However, the physical activity need only be of a very low-level to achieve such an increase; with our own study finding that intermittent body displacement (stepping) increases EE to 1.5-1.6 METs (Miles-Chan et al., 2017). The low-level activities that comprise a large component of daily-life (e.g., domestic and household activities like carrying shopping, ironing, washing dishes, etc.) therefore present an ideal opportunity to elevate EE sufficiently to impact body weight management. The energetic cost of these activities was historically well-characterized in the context of estimating energy requirements (Passmore et al., 1952; Passmore and Durnin, 1955). Although, due to the myriad of technological advances made over recent decades, designed to make household activities quicker and easier, these early estimations are now largely redundant. There is hence a need to revisit such domestic activities in order to determine their contemporary energy cost. Recent investigations have shown that despite improved technologies, routine household activities easily reach energetic costs sufficient to be classified as low-intensity ( $>1.5 \mathrm{METs}$ ) to moderate-intensity (>3 METs; Gunn et al., 2002; Withers et al., 2006; Goh et al., 2016). To what extent the energy cost of these low-level physical activities of everyday life would differ if undertaken while standing compared to sitting (or vice versa) remains to be investigated. However, difficulties arise when comparing between population and study groups owing to a lack of standardized tests to assess the energy cost of low-level physical 
activity. Furthermore, there is a need to explore human variability in this cost, which may have important implications for the efficacy of the use of low-level physical activity for body weight management. With the majority of daily-life activities consisting of both isometric and dynamic activity (Dulloo et al., 2017), we have recently developed and validated two such standardized methodologies; one involving an isometric leg press protocol of low-intensity (Sarafian et al., 2013), and the other a low-intensity cycle ergometer protocol (Fares et al., 2017). These standardized approaches are applicable to a vast range of population groups (i.e., healthy, elderly, or diseased populations) and pave the way for a more comprehensive examination of inter-individual variability in both our susceptibility to obesity and the efficacy of body weight maintenance strategies.

\section{CONCLUDING REMARKS}

Whilst altering posture represents a simple target for body weight management, the gains in EE achieved by changing postural allocation per-se are unlikely to be of significant importance. However, increases in postural transitioning, either alone, or in combination with low-level physical activities presents a much more efficacious method; with the relatively minor increases in EE easily accumulated over the course of our daily activities. Whether, breaking the sedentary threshold will lead to compensatory increases in energy intake (or not) remains to be

\section{REFERENCES}

Alexander, R. M. (1989). Optimization and gaits in the locomotion of vertebrates. Physiol. Rev. 69, 1199-1227.

Apfelbaum, M., Bostsarron, J., and Lacatis, D. (1971). Effect of caloric restriction and excessive caloric intake on energy expenditure. Am. J. Clin. Nutr. 24, 1405-1409.

Bandyopadhyay, B., and Chattopadhyay, H. (1980). Energy metabolism in male college students. Indian J. Med. Res. 71, 961-969.

Banerjee, B., Khew, K. S., and Saha, N. (1971). A comparative study of energy expenditure in some common daily activities of non-pregnant and pregnant Chinese, Malay and Indian women. J. Obstet. Gynaecol. Br. Commonw. 78, 113-116. doi: 10.1111/j.1471-0528.1971.tb00243.x

Banerjee, B., and Saha, N. (1972). Resting metabolic rate and energy cost of some common daily activities of trained and untrained tropical people: energy metabolism in training in Tropics. J. Sports Med. Phys. Fitness 12, 111-116.

Beers, E. A., Roemmich, J. N., Epstein, L. H., and Horvath, P. J. (2008). Increasing passive energy expenditure during clerical work. Eur. J. Appl. Physiol. 103, 353-360. doi: 10.1007/s00421-008-0713-y

Bergouignan, A., Latouche, C., Heywood, S., Grace, M. S., Reddy-Luthmoodoo, M., Natoli, A. K., et al. (2016). Frequent interruptions of sedentary time modulates contraction- and insulin-stimulated glucose uptake pathways in muscle: ancillary analysis from randomized clinical trials. Sci. Rep. 6:32044. doi: 10.1038/srep32044

Bergstrom, M., and Hultman, E. (1988). Energy cost and fatigue during intermittent electrical stimulation of human skeletal muscle. J. Appl. Physiol. $65,1500-1505$

Blaszczyk, J. W., Cieslinska-Swider, J., Plewa, M., Zahorska-Markiewicz, B., and Markiewicz, A. (2009). Effects of excessive body weight on postural control. J. Biomech. 42, 1295-1300. doi: 10.1016/j.jbiomech.2009.03.006

Bleiberg, F. M., Brun, T. A., Goihman, S., and Gouba, E. (1980). Duration of activities and energy expenditure of female farmers in dry and rainy seasons in Upper-Volta. Br. J. Nutr. 43, 71-82. doi: 10.1079/BJN19800065

Blundell, J. E., Gibbons, C., Caudwell, P., Finlayson, G., and Hopkins, M. (2015). Appetite control and energy balance: impact of exercise. Obes. Rev. 16(Suppl. 1), 67-76. doi: 10.1111/obr.12257 investigated. However, it should be emphasized that not only are these types of movements both attainable and sustainable by the majority of the general population, but such modest increases in physical activity may lead to a better coupling of energy intake to energy expenditure, and hence facilitate the achievement of energy balance-as suggested by the J-shaped curves of Mayer et al. (1956) and more recently revisited by Blundell et al. (2015) and Hopkins and Blundell (2016). Therefore, with suggestions that an energy imbalance of $100-200 \mathrm{kcal} /$ day (i.e., $<10 \%$ of average daily energy expenditure) may be sufficient to address the obesity crisis at the broad population level (Butte and Ellis, 2003; Hill et al., 2003), the role of posture allocations coupled with inter-individual variability in our metabolic response to low-level physical activities deserve considerable research attention.

\section{AUTHOR CONTRIBUTIONS}

All authors listed, have made substantial, direct, and intellectual contribution to the work, and approved it for publication.

\section{FUNDING}

This research work was supported in part by University of Fribourg intramural funding and in part by the Swiss National Science Foundation (Grant Number: 310030_152870).

Brun, T., Bleiberg, F., and Goihman, S. (1981). Energy expenditure of male farmers in dry and rainy seasons in Upper-Volta. Br. J. Nutr. 45, 67-75. doi: 10.1079/BJN19810077

Buckley, J. P., Mellor, D. D., Morris, M., and Joseph, F. (2014). Standingbased office work shows encouraging signs of attenuating postprandial glycaemic excursion. Occup. Environ. Med. 71, 109-111. doi: 10.1136/oemed-2013-101823

Butte, N. F., and Ellis, K. J. (2003). Comment on "Obesity and the environment: where do we go from here?” Science 301, 598; author reply:598. doi: 10.1126/science. 1085985

Ceesay, S. M., Prentice, A. M., Day, K. C., Murgatroyd, P. R., Goldberg, G. R., Scott, W., et al. (1989). The use of heart rate monitoring in the estimation of energy expenditure: a validation study using indirect whole-body calorimetry. $\mathrm{Br}$. J. Nutr. 61, 175-186. doi: 10.1079/BJN19890107

Chasiotis, D., Bergstrom, M., and Hultman, E. (1987). ATP utilization and force during intermittent and continuous muscle contractions. J. Appl. Physiol. 63, 167-174.

Cole, A. H., and Ogbe, J. O. (1987). Energy intake, expenditure and pattern of daily activity of Nigerian male students. Br. J. Nutr. 58, 357-367. doi: 10.1079/BJN19870105

Corbeil, P., Simoneau, M., Rancourt, D., Tremblay, A., and Teasdale, N. (2001). Increased risk for falling associated with obesity: mathematical modeling of postural control. IEEE Trans. Neural Syst. Rehabil. Eng. 9, 126-136. doi: $10.1109 / 7333.928572$

Creasy, S. A., Rogers, R. J., Byard, T. D., Kowalsky, R. J., and Jakicic, J. M. (2016). Energy expenditure during acute periods of sitting, standing, and walking. $J$. Phys. Act. Health 13, 573-578. doi: 10.1123/jpah.2015-0419

Cruz-Gomez, N. S., Plascencia, G., Villanueva-Padron, L. A., and Jauregui-Renaud, K. (2011). Influence of obesity and gender on the postural stability during upright stance. Obes. Facts 4, 212-217. doi: 10.1159/000329408

de Guzman, M. P. E., Cabrera, J. P., Basconcillo, R. O., Gaurano, A. L., Yuchingtat, G. P., Tan, R. M., et al. (1978). A study of the energy expenditure, dietary intake and pattern of daily activity among various occupational groups. Clerk-typist. Philipp. J. Nutr. 31, 147-156.

de Guzman, M. P. E., Cabrera, J. P., Yuchingtat, G. P., Abanto, Z. U., and Gaurano, A. L. (1984). A study of the energy expenditure, dietary intake and pattern of 
daily activity among various occupational groups. Laguna Rice farmers. Philipp. J. Nutr. 37, 163-174.

de Guzman, M. P. E., Recto, R. C., Cabrera, J. P., Basconcillo, R. O., Gaurano, A. L., Yuchingtat, G. P., et al. (1979). A study of the energy expenditure, dietary intake and pattern of daily activity among various occupational groups. Textile Mill workers. Philipp. J. Nutr. 32, 134-148.

Donald, K. W., and Davidson, W. M. (1954). Oxygen uptake of booted and fin swimming divers. J. Appl. Physiol. 7, 31-37.

Dulloo, A. G., Jacquet, J., Montani, J. P., and Schutz, Y. (2012). Adaptive thermogenesis in human body weight regulation: more of a concept than a measurable entity? Obes. Rev. 13(Suppl. 2), 105-121. doi: 10.1111/j.1467-789X.2012.01041.x

Dulloo, A. G., Miles-Chan, J. L., Montani, J. P., and Schutz, Y. (2017). Isometric thermogenesis at rest and during movement: a neglected variable in energy expenditure and obesity predisposition. Obes. Rev. 18(Suppl. 1), 56-64. doi: $10.1111 /$ obr.12505

Durnin, J. V. G. A., and Passmore, R. (1967). Energy, Work and Leisure. London: Heinemann.

Edholm, O. G., Fletcher, J. G., Widdowson, E. M., and McCance, R. A. (1955). The energy expenditure and food intake of individual men. Br. J. Nutr. 9, 286-300. doi: 10.1079/BJN19550040

Edmundson, W. C., and Edmundson, S. A. (1988). Food intake and work allocation of male and female farmers in an impoverished Indian village. Br. J. Nutr. 60, 433-439. doi: 10.1079/BJN19880115

Fares, E. J., Charriere, N., Montani, J. P., Schutz, Y., Dulloo, A. G., and MilesChan, J. L. (2016). Energy expenditure and substrate oxidation in response to side-alternating whole body vibration across three commonly-used vibration frequencies. PLoS ONE 11:e0151552. doi: 10.1371/journal.pone.0151552

Fares, E. J., Isacco, L., Monnard, C. R., Miles-Chan, J. L., Montani, J. P., Schutz, Y., et al. (2017). Reliability of low power cycling efficiency in energy expenditure phenotyping of inactive men and women. Physiol. Rep. 5:e13233. doi: 10.14814/phy2.13233

Fountaine, C. J., Johann, J., Skalko, C., and Liguori, G. A. (2016). Metabolic and energy cost of sitting, standing, and a novel sitting/stepping protocol in recreationally active college students. Int. J. Exerc. Sci. 9, 223-229.

Garry, R. C., Passmore, R., Warnock, G. M., and Durnin, J. V. (1955). Studies on expenditure of energy and consumption of food by miners and clerks, Fife, Scotland, 1952. Spec. Rep. Ser. Med. Res. Counc. 289, 1-70.

Geissler, C. A., and Aldouri, M. S. H. (1985). Racial differences in the energy cost of standardised activities. Ann. Nutr. Metab. 29, 40-47. doi: 10.1159/000176952

Geissler, C., Brun, T., Mirbagheri, I., Soheli, A., Naghibi, A., and Hedayat, H. (1981). The energy expenditure of female carpet weavers and rural women in Iran. Am. J. Clin. Nutr. 34, 2776-2783.

Gibbs, B. B., Kowalsky, R. J., Perdomo, S. J., Grier, M., and Jakicic, J. M. (2017). Energy expenditure of deskwork when sitting, standing or alternating positions. Occup. Med. 67, 121-127. doi: 10.1093/occmed/kqw115

Gilleard, W., and Smith, T. (2007). Effect of obesity on posture and hip joint moments during a standing task, and trunk forward flexion motion. Int. J. Obes. 31, 267-271. doi: 10.1038/sj.ijo.0803430

Goh, H. J., Govindharajulu, P., Camps, S. G., Tan, S. Y., and Henry, C. J. (2016). Gross and relative energy cost of domestic household activities in Asian men. Eur. J. Clin. Nutr. 70, 1414-1419. doi: 10.1038/ejcn.2016.134

Gregory, D. E., Dunk, N. M., and Callaghan, J. P. (2006). Stability ball versus office chair: comparison of muscle activation and lumbar spine posture during prolonged sitting. Hum. Factors 48, 142-153. doi: $10.1518 / 001872006776412243$

Gunn, S. M., Brooks, A. G., Withers, R. T., Gore, C. J., Owen, N., Booth, M. L., et al. (2002). Determining energy expenditure during some household and garden tasks. Med. Sci. Sports Exerc. 34, 895-902. doi: 10.1097/00005768-200205000-00026

Gupta, N., Hallman, D. M., Mathiassen, S. E., Aadahl, M., Jorgensen, M. B., and Holtermann, A. (2016). Are temporal patterns of sitting associated with obesity among blue-collar workers? A cross sectional study using accelerometers. BMC Public Health 16:148. doi: 10.1186/s12889-016-2803-9

Hamilton, M. T., Healy, G. N., Dunstan, D. W., Zderic, T. W., and Owen, N. (2008). Too little exercise and too much sitting: inactivity physiology and the need for new recommendations on sedentary behavior. Curr. Cardiovasc. Risk Rep. 2, 292-298. doi: 10.1007/s12170-008-0054-8
Hatamoto, Y., Yamada, Y., Higaki, Y., and Tanaka, H. (2016). A novel approach for measuring energy expenditure of a single sit-to-stand movement. Eur. J. Appl. Physiol. 116, 997-1004. doi: 10.1007/s00421-016-3355-5

Healy, G. N., Dunstan, D. W., Salmon, J., Cerin, E., Shaw, J. E., Zimmet, P. Z., et al. (2008). Breaks in sedentary time: beneficial associations with metabolic risk. Diabetes Care 31, 661-666. doi: 10.2337/dc07-2046

Henson, J., Dunstan, D. W., Davies, M. J., and Yates, T. (2016). Sedentary behaviour as a new behavioural target in the prevention and treatment of type 2 diabetes. Diabetes Metab. Res. Rev. 32(Suppl. 1), 213-220. doi: 10.1002/dmrr.2759

Hill, J. O., Wyatt, H. R., Reed, G. W., and Peters, J. C. (2003). Obesity and the environment: where do we go from here? Science 299, 853-855. doi: $10.1126 /$ science. 1079857

Hogan, M. C., Ingham, E., and Kurdak, S. S. (1998). Contraction duration affects metabolic energy cost and fatigue in skeletal muscle. Am. J. Physiol. 274, E397-E402.

Honda, T., Chen, S., Yonemoto, K., Kishimoto, H., Chen, T., Narazaki, K., et al. (2016). Sedentary bout durations and metabolic syndrome among working adults: a prospective cohort study. BMC Public Health 16:888. doi: 10.1186/s12889-016-3570-3

Hopkins, M., and Blundell, J. E. (2016). Energy balance, body composition, sedentariness and appetite regulation: pathways to obesity. Clin. Sci. 130:1615. doi: $10.1042 / C S 20160006$

Johannsen, D. L., Welk, G. J., Sharp, R. L., and Flakoll, P. J. (2008). Differences in daily energy expenditure in lean and obese women: the role of posture allocation. Obesity 16, 34-39. doi: 10.1038/oby.2007.15

Jones, C. D., Jarjou, M. S., Whitehead, R. G., and Jequier, E. (1987). Fatness and the energy cost of carrying loads in African women. Lancet 2, 1331-1332. doi: 10.1016/S0140-6736(87)91221-9

Judice, P. B., Hamilton, M. T., Sardinha, L. B., Zderic, T. W., and Silva, A. M. (2016). What is the metabolic and energy cost of sitting, standing and sit/stand transitions? Eur. J. Appl. Physiol. 116, 263-273. doi: 10.1007/s00421-015-3279-5

Kanade, A. N., Gokhale, M. K., and Rao, S. (2001). Energy costs of standard activities among Indian adults. Eur. J. Clin. Nutr. 55, 708-713. doi: 10.1038/sj.ejcn.1601211

Katzmarzyk, P. T., Leonard, W. R., Stephen, M. A., Berti, P. R., and Ross, A. G. (1996). Differences between observed and predicted energy costs at rest and during exercise in three subsistence-level populations. Am. J. Phys. Anthropol. 99, 537-545. doi: 10.1002/ajpa.1330990402

Kingma, I., and van Dieen, J. H. (2009). Static and dynamic postural loadings during computer work in females: sitting on an office chair versus sitting on an exercise ball. Appl. Ergon. 40, 199-205. doi: 10.1016/j.apergo.2008.04.004

Koller, J. R., Jacobs, D. A., Ferris, D. P., and Remy, C. D. (2015). Learning to walk with an adaptive gain proportional myoelectric controller for a robotic ankle exoskeleton. J. Neuroeng. Rehabil. 12:97. doi: 10.1186/s12984-015-0086-5

Landry, S. C., Nigg, B. M., and Tecante, K. E. (2010). Standing in an unstable shoe increases postural sway and muscle activity of selected smaller extrinsic foot muscles. Gait Posture 32, 215-219. doi: 10.1016/j.gaitpost.2010.04.018

Lawrence, M., Singh, J., Lawrence, F., and Whitehead, R. G. (1985). The energy cost of common daily activities in African women: increased expenditure in pregnancy? Am. J. Clin. Nutr. 42, 753-763.

Levine, J. A., and Miller, J. M. (2007). The energy expenditure of using a "walkand-work" desk for office workers with obesity. Br. J. Sports Med. 41, 558-561. doi: 10.1136/bjsm.2006.032755

Levine, J. A., Eberhardt, N. L., and Jensen, M. D. (1999). Role of nonexercise activity thermogenesis in resistance to fat gain in humans. Science 283, 212-214. doi: $10.1126 /$ science. 283.5399 .212

Levine, J. A., Lanningham-Foster, L. M., McCrady, S. K., Krizan, A. C., Olson, L. R., Kane, P. H., et al. (2005). Interindividual variation in posture allocation: possible role in human obesity. Science 307, 584-586. doi: $10.1126 /$ science. 1106561

Levine, J. A., Schleusner, S. J., and Jensen, M. D. (2000). Energy expenditure of nonexercise activity. Am. J. Clin. Nutr. 72, 1451-1454.

Li, J., and Yan, W. Y. (1991). The energy expenditure and nutritional status of college students. I. The energy cost and the total energy expenditure per day. Biomed. Environ. Sci. 4, 295-303.

Lloyd, R., Parr, B., Davies, S., and Cooke, C. (2010). No 'free ride' for African women: a comparison of head-loading versus back-loading among Xhosa women. S. Afr. J. Sci. 106:153. doi: 10.4102/sajs.v106i3/4.153 
Maffiuletti, N. A., Malatesta, D., Agosti, F., and Sartorio, A. (2012). Unstable shoes increase energy expenditure of obese patients. Am. J. Med. 125, 513-516. doi: 10.1016/j.amjmed.2012.01.001

Malhotra, M. S., Chandra, U., and Sridharan, K. (1976). Dietary intake and energy requirement of Indian submariners in tropical waters. Ergonomics 19, 141-148. doi: 10.1080/00140137608931526

Maloiy, G. M., Heglund, N. C., Prager, L. M., Cavagna, G. A., and Taylor, C. R. (1986). Energetic cost of carrying loads: have African women discovered an economic way? Nature 319, 668-669. doi: 10.1038/319668a0

Mayer, J., Roy, P., and Mitra, K. P. (1956). Relation between caloric intake, body weight, and physical work: studies in an industrial male population in West Bengal. Am. J. Clin. Nutr. 4, 169-175.

McAlpine, D. A., Manohar, C. U., McCrady, S. K., Hensrud, D., and Levine, J. A. (2007). An office-place stepping device to promote workplace physical activity. Br. J. Sports Med. 41, 903-907. doi: 10.1136/bjsm.2006.034900

McGill, S. M., Kavcic, N. S., and Harvey, E. (2006). Sitting on a chair or an exercise ball: various perspectives to guide decision making. Clin. Biomech. 21, 353-360. doi: 10.1016/j.clinbiomech.2005.11.006

Miles-Chan, J. L., Fares, E. J., Berkachy, R., Jacquet, P., Isacco, L., Schutz, Y., et al. (2017). Standing economy: does the heterogeneity in the energy cost of posture maintenance reside in differential patterns of spontaneous weight-shifting? Eur. J. Appl. Physiol. 117, 795-807. doi: 10.1007/s00421-017-3563-7

Miles-Chan, J. L., Sarafian, D., Montani, J. P., Schutz, Y., and Dulloo, A. (2013). Heterogeneity in the energy cost of posture maintenance during standing relative to sitting: phenotyping according to magnitude and time-course. PLoS ONE 8:e65827. doi: 10.1371/journal.pone.0065827

Miles-Chan, J. L., Sarafian, D., Montani, J. P., Schutz, Y., and Dulloo, A. G. (2014). Sitting comfortably versus lying down: is there really a difference in energy expenditure? Clin. Nutr. 33, 175-178. doi: 10.1016/j.clnu.2013.11.009

Miller, D. S. (1982). Factors affecting energy expenditure. Proc. Nutr. Soc. 41, 193-202. doi: 10.1079/PNS19820030

Monnard, C. R., and Miles-Chan, J. L. (2017). Energy cost of standing in a multi-ethnic cohort: are energy-savers a minority or the majority? PLoS ONE 12:e0169478. doi: 10.1371/journal.pone.0169478

Ng, S. W., and Popkin, B. (2012). Time use and physical activity: a shift away from movement across the globe. Obes. Rev. 13, 659-680. doi: 10.1111/j.1467-789X.2011.00982.x

Norgan, N. G., Ferro-Luzzi, A., and Durnin, J. V. (1974). The energy and nutrient intake and the energy expenditure of 204 New Guinean adults. Philos. Trans. $R$. Soc. Lond. B. Biol. Sci. 268, 309-348. doi: 10.1098/rstb.1974.0033

Passmore, R., and Durnin, J. V. (1955). Human energy expenditure. Physiol. Rev. 35, 801-840.

Passmore, R., Thomson, J. G., Warnock, G. M., Dixon, C. M., Kitchin, A. H., Smith, G., et al. (1952). A balance sheet of the estimation of energy intake and energy expenditure as measured by indirect calorimetry, using the Kofranyi-Michaelis calorimeter. Br. J. Nutr. 6, 253-264. doi: 10.1079/BJN19520028

Poppitt, S. D., Prentice, A. M., Jequier, E., Schutz, Y., and Whitehead, R. G. (1993). Evidence of energy sparing in Gambian women during pregnancy: a longitudinal study using whole-body calorimetry. Am. J. Clin. Nutr. 57, 353-364.

Rao, S., Gokhale, M., and Kanade, A. (2008). Energy costs of daily activities for women in rural India. Public Health Nutr. 11, 142-150. doi: $10.1017 /$ S1368980007000055

Reiff, C., Marlatt, K., and Dengel, D. R. (2012). Difference in caloric expenditure in sitting versus standing desks. J. Phys. Act. Health 9, 1009-1011. doi: 10.1123/jpah.9.7.1009

Sarafian, D., Miles-Chan, J. L., Yepuri, G., Montani, J. P., Schutz, Y., and Dulloo, A. G. (2013). A standardized approach to study human variability in isometric thermogenesis during low-intensity physical activity. Front. Physiol. 4:155. doi: 10.3389/fphys.2013.00155

Sedentary Behaviour Research Network (2012). Letter to the editor: standardized use of the terms "sedentary" and "sedentary behaviours." Appl. Physiol. Nutr. Metab. 37, 540-542. doi: 10.1139/h2012-024

Selinger, J. C., O’Connor, S. M., Wong, J. D., and Donelan, J. M. (2015). Humans can continuously optimize energetic cost during walking. Curr. Biol. 25, 2452-2456. doi: 10.1016/j.cub.2015.08.016

Singh, D., Park, W., Levy, M. S., and Jung, E. S. (2009). The effects of obesity and standing time on postural sway during prolonged quiet standing. Ergonomics 52, 977-986. doi: 10.1080/00140130902 777636

Speck, R. M., and Schmitz, K. H. (2011). Energy expenditure comparison: a pilot study of standing instead of sitting at work for obesity prevention. Prev. Med. 52, 283-284. doi: 10.1016/j.ypmed.2011.02.002

Spriet, L. L., Soderlund, K., and Hultman, E. (1988). Energy cost and metabolic regulation during intermittent and continuous tetanic contractions in human skeletal muscle. Can. J. Physiol. Pharmacol. 66, 134-139. doi: 10.1139/ y88-024

Spurr, G. B., Prentice, A. M., Murgatroyd, P. R., Goldberg, G. R., Reina, J. C., and Christman, N. T. (1988). Energy expenditure from minute-by-minute heartrate recording: comparison with indirect calorimetry. Am. J. Clin. Nutr. 48, $552-559$.

Steeves, J. A., Thompson, D. L., and Bassett, D. R. Jr. (2012). Energy cost of stepping in place while watching television commercials. Med. Sci. Sports Exerc. 44, 330-335. doi: 10.1249/MSS.0b013e31822d797e

Strickland, S. S., and Ulijaszek, S. J. (1990). Energetic cost of standard activities in Gurkha and British soldiers. Ann. Hum. Biol. 17, 133-144. doi: 10.1080/03014469000000882

Sujatha, T., Shatrugna, V., Venkataramana, Y., and Begum, N. (2000). Energy expenditure on household, childcare and occupational activities of women from urban poor households. Br. J. Nutr. 83, 497-503. doi: $10.1017 /$ S0007114500000635

Tigbe, W. W., Granat, M. H., Sattar, N., and Lean, M. E. (2017). Time spent in sedentary posture is associated with waist circumference and cardiovascular risk. Int. J. Obes. 41, 689-696. doi: 10.1038/ijo.2017.30

Tucker, V. A. (1970). Energetic cost of locomotion in animals. Comp. Biochem. Physiol. 34, 841-846. doi: 10.1016/0010-406X(70)91006-6

Vaz, M., Karaolis, N., Draper, A., and Shetty, P. (2005). A compilation of energy costs of physical activities. Public Health Nutr. 8, 1153-1183. doi: 10.1079/PHN2005802

Villarrasa-Sapina, I., Garcia-Masso, X., Serra-Ano, P., GarciaLucerga, C., Gonzalez, L. M., and Lurbe, E. (2016). Differences in intermittent postural control between normal-weight and obese children. Gait Posture 49, 1-6. doi: 10.1016/j.gaitpost.2016. 06.012

Viteri, F. E., Torun, B., Galicia, J. C., and Herrera, E. (1971). Determining energy costs of agricultural activities by respirometer and energy balance techniques. Am. J. Clin. Nutr. 24, 1418-1430.

Wayman, E. (2012). Becoming Human: The Evolution of Walking Upright. Available online at: http://www.smithsonianmag.com/science-nature/becominghuman-the-evolution- of-walking-upright-13837658/

Whybrow, S., Ritz, P., Horgan, G. W., and Stubbs, R. J. (2013). An evaluation of the IDEEA activity monitor for estimating energy expenditure. Br. J. Nutr. 109, 173-183. doi: 10.1017/S0007114512000645

Withers, R. T., Brooks, A. G., Gunn, S. M., Plummer, J. L., Gore, C. J., and Cormack, J. (2006). Self-selected exercise intensity during household/garden activities and walking in 55 to 65-year-old females. Eur. J. Appl. Physiol. 97, 494-504. doi: 10.1007/s00421-006-0177-x

Young, D. R., Hivert, M. F., Alhassan, S., Camhi, S. M., Ferguson, J. F., Katzmarzyk, P. T., et al. (2016). Sedentary behavior and cardiovascular morbidity and mortality: a science advisory from the american heart association. Circulation 134, e262-e279. doi: 10.1161/CIR.0000000000 000440

Zurlo, F., Ferraro, R. T., Fontvielle, A. M., Rising, R., Bogardus, C., and Ravussin, E. (1992). Spontaneous physical activity and obesity: cross-sectional and longitudinal studies in Pima Indians. Am. J. Physiol. 263, E296-E300.

Conflict of Interest Statement: The authors declare that the research was conducted in the absence of any commercial or financial relationships that could be construed as a potential conflict of interest.

Copyright (C) 2017 Miles-Chan and Dulloo. This is an open-access article distributed under the terms of the Creative Commons Attribution License (CC BY). The use, distribution or reproduction in other forums is permitted, provided the original author(s) or licensor are credited and that the original publication in this journal is cited, in accordance with accepted academic practice. No use, distribution or reproduction is permitted which does not comply with these terms. 